\title{
Content Validity of a Self-Management Behavior Assessment Tool for Adult Post-Renal Transplant Recipients Using a Modified Delphi Method
}

\author{
Takahiro Ohashi' ${ }^{1,2}$, Chiharu Akazawa1 \\ ${ }^{1}$ Faculty of Nursing, School of Nursing, Osaka Medical and Pharmaceutical University, Osaka, Japan \\ ${ }^{2}$ Doctoral Program, Graduate School of Nursing, Osaka Medical and Pharmaceutical University, Osaka, Japan \\ Email: takahiro.ohashi@ompu.ac.jp
}

How to cite this paper: Ohashi, T. and Akazawa, C. (2022) Content Validity of a SelfManagement Behavior Assessment Tool for Adult Post-Renal Transplant Recipients Using a Modified Delphi Method. Health, 14, 7095.

https://doi.org/10.4236/health.2022.141007

Received: December 13, 2021

Accepted: January 18, 2022

Published: January 21, 2022

\section{Copyright $\odot 2022$ by author(s) and} Scientific Research Publishing Inc. This work is licensed under the Creative Commons Attribution International License (CC BY 4.0).

http://creativecommons.org/licenses/by/4.0/

\begin{abstract}
Background: Self-management is important for post-renal transplant recipients to resolve renal dysfunction, heart failure, and post-transplant psychosocial issues, and to maintain transplant kidney function, etc. However, because recipients may be unable to adequately self-manage, healthcare providers need to provide self-management support for recipients to improve their skills and confidence in managing their disease. However, it is difficult to comprehensively assess the self-management behaviors in a busy outpatient support setting. Furthermore, since there are no uniform standards for assessment, it is based on the experience and abilities of medical personnel. Therefore, self-management behavior of post-renal transplant recipients is not sufficiently evaluated. Objective: This study aimed to evaluate content validity of a tool that can assess self-management behaviors of adult post-renal transplant recipients, consisting of consensus components from experts familiar with the follow-up of adult post-renal transplant recipients. Methods: A three-round modified Delphi method was used to assess the self-management behaviors of adult post-renal transplant recipients by a panel of experts consisting of certified transplant recipient coordinators, physicians, outpatient nurses, and researchers familiar with the follow-up of post-renal transplant recipients. Regarding management behaviors of adult post-renal transplant recipients, the experts rated the appropriateness and validity of each item using a Likert scale. Consensus ratings from the experts were made by calculating the median, interquartile range, and interquartile range percentage. In the third round, an item-level content validity index was calculated to assess content validity. Conclusions: The 41 -item self-management beha-
\end{abstract}


vior scale for kidney transplant recipients assessed self-management behaviors in five domains: medication, exercise, fluids and diet, disease and symptom prevention and management, and psychosocial adjustment. The content validity of this tool was confirmed, and it can be used to more easily assess the recipients' self-management behaviors in the post-renal transplant follow-up. This tool can potentially contribute to the maintenance of transplant kidney function and high QOL in recipients.

\section{Keywords}

Post-Renal Transplant, Recipient, Self-Management, Modified

Delphi Method

\section{Introduction}

In recent years, advances in medical technology and immunosuppressive drugs have dramatically improved the survival rate of post-renal transplant recipients and the survival rate of transplanted kidneys. Many recipients are now able to live a life free from uremia and maintenance dialysis after transplantation. However, there are still challenges in improving long-term outcomes, and as noted, "All kidney transplant recipients should be considered to have Chronic Kidney Disease (CKD) regardless of GFR level or renal impairment markers." [1] Recipients are always at risk for graft rejection and renal dysfunction due to immunosuppressive drugs. Additionally, death with functioning grafts (DWFG) due to infections, malignancies, post-transplant diabetes (NODAT), post-transplant hypertension, and cardiovascular disease (CVD) caused by immunosuppressive drugs is also an issue.

Therefore, post-renal transplant recipients are required to perform comprehensive and continuous self-management [2], defined as "managing one or more chronic conditions (e.g., symptoms, treatment, physical and psychosocial consequences, and lifestyle changes) and integrating them into daily life to achieve optimal quality of life." [3] As a chronic disease patient with CKD it is necessary to make efforts for prevention, early detection, and early treatment of CKD exacerbation and CVD.

However, previous studies have reported that recipients struggle with the psychological and social demands of living with their post-transplant condition [4]. This is in addition to neglect of immunosuppressive medications [5], inadequate monitoring of graft rejection and infection prevention [6], and lack of physical activity [7], which may lead to inadequate self-management. Therefore, to improve long-term outcomes after transplantation, health care providers need to intervene to increase recipients' disease management skills and confidence such that they are aware of their own post-transplant health problems and can manage by themselves [8].

However, in the author's experience, outpatient support for renal transplanta- 
tion in Japan has been limited to checking renal function and immunosuppressive medication by physicians. Moreover, there may be insufficient support by certified transplant recipient coordinators (RTCs) and outpatient nurses, who are experts in follow-up after renal transplantation. In fact, previous studies have shown that post-transplant care is not adequately supported by RTCs and outpatient nurses. They have pointed out that post-transplant self-management support focuses on promoting medication adherence and self-monitoring [9] [10]. Conversely, support for lifestyle and psychosocial statuses, such as diet and exercise, is not sufficiently provided. This is because it is difficult for outpatient nurses who are not familiar with RTCs and kidney transplantation, of which there are only one or two per outpatient clinic, to comprehensively assess the self-management behaviors of dozens of recipients per day. In addition, there is no uniform standard for evaluating self-management behaviors, and evaluations are conducted based on the experience and abilities of medical personnel. Consequently, decisions on support are made based on these evaluations.

One strategy to overcome this situation is to create a tool that allows even outpatient nurses who are not familiar with kidney transplantation to easily assess the self-management behavior of post-renal transplant recipients. The use of such a tool is expected to reduce the number of overlooked issues in recipient self-management behavior in busy settings. However, at this time, no assessment tool has reached consensus among healthcare providers conducting post-renal transplant follow-up. Since the actual follow-up of post-renal transplant recipients varies by institution and provider, it is necessary to develop a tool that has the consensus of experts who are at the forefront of follow-up of post-renal transplant recipients. Resultantly, it makes it widely applicable in actual clinical practice.

Considering that the challenges of post-renal transplant self-management may differ significantly when developmental stages are taken into account, the target population for the tools developed in this study will be adult post-renal transplant recipients.

\section{Objective}

This study aims to evaluate content validity of a tool that can assess self-management behaviors of adult post-renal transplant recipients, consisting of expert consensus constructs.

\section{Methods}

\section{1) Research Design}

We developed the "Self-management behavior scale for kidney transplant recipients (draft)" and conducted a survey using the modified Delphi method. The flow of this study is shown in Figure 1.

2) Development of "Self-management behavior scale for kidney transplant recipients (draft) 


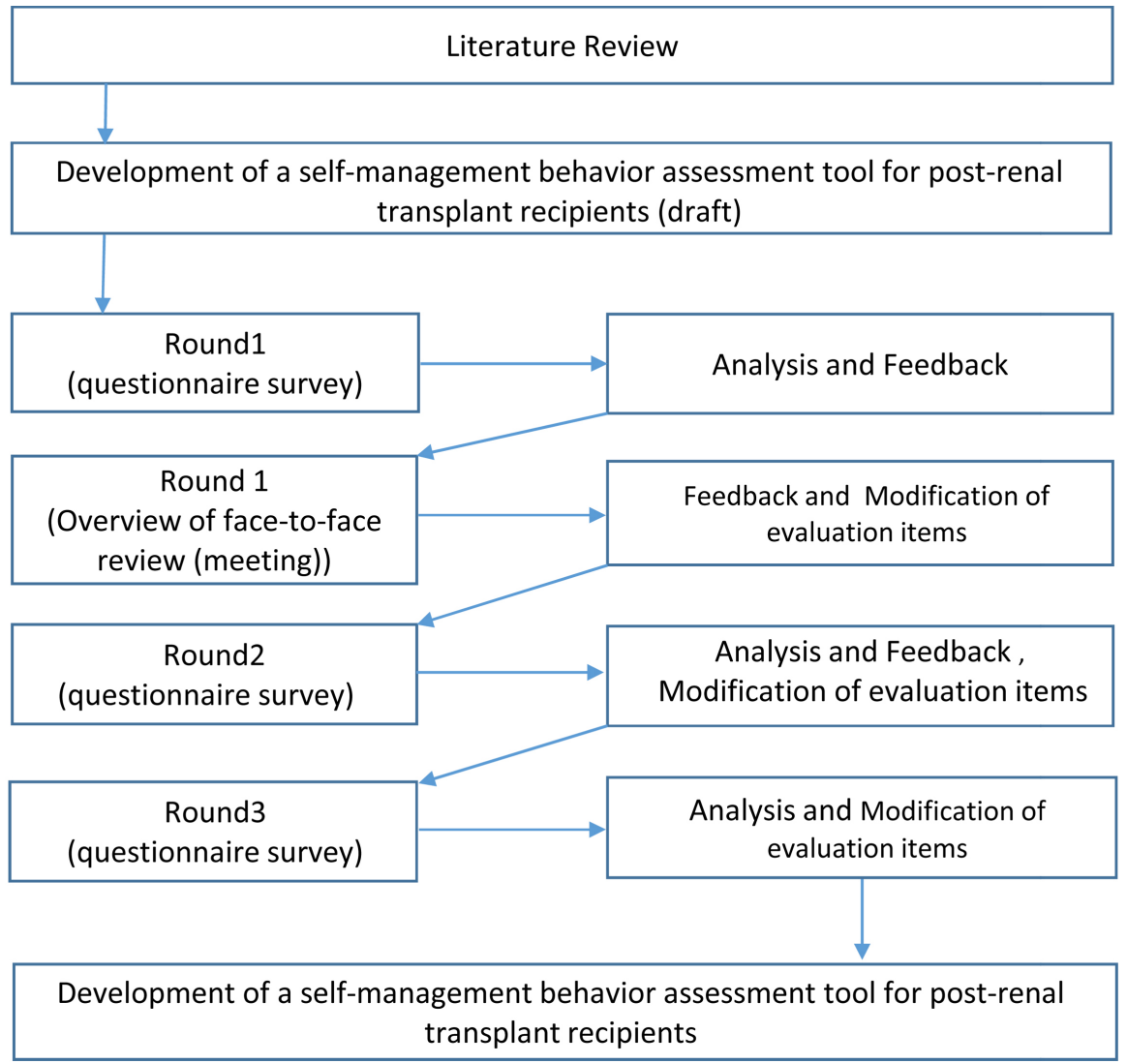

Figure 1. Flow of the research.

Based on a review of previous literature reporting on the self-management behaviors required for adult post-renal transplant recipients (hereafter referred to as "recipients") and their current status, as well as the KDIGO Clinical Practice Guideline for the Care of Kidney Transplant Recipients' [11] self-management behaviors were categorized into 5 domains: medication, exercise, fluid and nutrition, disease and symptom prevention and management, and psychosocial adjustment.

Thereafter, the structure of the items and the wording of the questions were examined so that the items could be answered without misunderstanding by any generation of recipients and could specifically assess self-management behavior from both the medical and the recipient's life perspectives. The items were then refined with the supervision of a researcher who is familiar with transplantation medicine and scale development at the researcher's institution.

As a result, we developed the "Self-management behavior scale for kidney transplant recipients" (hereinafter referred to as the assessment tool) with 41 items in 5 domains (Table 1). The recipient was asked to rate each item on a 5 -point scale from "0: not at all applicable" to " 4 : very applicable".

3) Examination of the content validity of the evaluation tool using the modified Delphi method

In this study, we used the modified Delphi method, which is one of the 
Table 1. Assessment items for self-management behaviors in each round.

\begin{tabular}{|c|c|c|c|c|}
\hline Field & $\begin{array}{c}\text { Item } \\
\text { number }\end{array}$ & $\begin{array}{l}\text { Round } 1 \text { survey item } \\
\text { (first draft) }\end{array}$ & Round 2 survey item & Round 3 survey item \\
\hline \multirow{10}{*}{ 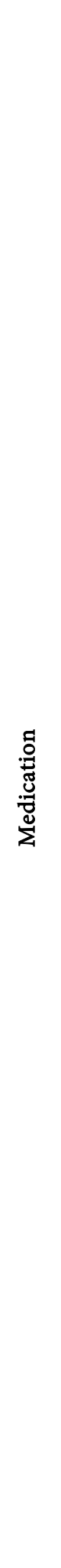 } & (1) & $\begin{array}{l}\text { (With some medicine) I } \\
\text { sometimes take a larger (or } \\
\text { less) dose than prescribed }\end{array}$ & $\begin{array}{l}\text { Except medicine permitted by } \\
\text { my doctor, I never take more } \\
\text { (or less) dose than prescribed }\end{array}$ & $\begin{array}{l}\text { I never take more (or less) } \\
\text { than the prescribed dose of } \\
\text { immunosuppressive drugs or } \\
\text { any other medicine }\end{array}$ \\
\hline & (2) & $\begin{array}{l}\text { (With some medicine) I } \\
\text { sometimes deviate from the } \\
\text { prescribed time to take it }\end{array}$ & $\begin{array}{l}\text { Except medicine permitted by } \\
\text { my doctor, I never deviate } \\
\text { from the prescribed time by } \\
\text { at least } 2 \text { hours }\end{array}$ & $\begin{array}{l}\text { I never deviate from the } \\
\text { prescribed time by at least } 2 \\
\text { hours when taking } \\
\text { immunosuppressive } \\
\text { drugs or any other medicine }\end{array}$ \\
\hline & (3) & $\begin{array}{l}\text { (With some medicine) I } \\
\text { sometimes forget to take it }\end{array}$ & $\begin{array}{l}\text { Except medicine permitted by } \\
\text { my doctor, I never forget to } \\
\text { take my medicine }\end{array}$ & $\begin{array}{l}\text { I never forget to take my } \\
\text { medicine, be it an } \\
\text { immunosuppressive } \\
\text { drug or any other medicine }\end{array}$ \\
\hline & (4) & $\begin{array}{l}\text { I sometimes run out of stock } \\
\text { of the medicine }\end{array}$ & - & - \\
\hline & (5) & - & $\begin{array}{l}\text { I always keep the stock of the } \\
\text { medicine for two weeks on } \\
\text { hand just in case }\end{array}$ & (No revision) \\
\hline & (6) & - & $\begin{array}{l}\text { I have not kept medicine that I } \\
\text { forgot to take as extras (stock) } \\
\text { without my doctor's permission }\end{array}$ & $\begin{array}{l}\text { I have not kept medicine that I } \\
\text { forgot to take as extras (stock), } \\
\text { nor thrown it out, without my } \\
\text { doctor's permission }\end{array}$ \\
\hline & (7) & $\begin{array}{l}\text { I haven't thought of a way to } \\
\text { remember not to forget to } \\
\text { take my medicine or take } \\
\text { the wrong one }\end{array}$ & $\begin{array}{l}\text { I have thought of a way to } \\
\text { prevent forgetting to take my } \\
\text { medicine or taking the wrong } \\
\text { one (or I never forget to take it) }\end{array}$ & (No revision) \\
\hline & (8) & $\begin{array}{l}\text { Sometimes I do not ask for } \\
\text { clarification even if there is } \\
\text { something I do not understand } \\
\text { or am confused about } \\
\text { related to my medicine }\end{array}$ & $\begin{array}{l}\text { I make sure to ask my medical } \\
\text { professionals if there is } \\
\text { anything regarding my } \\
\text { medicine that I am not sure } \\
\text { about or have a trouble }\end{array}$ & (No revision) \\
\hline & (9) & $\begin{array}{l}\text { I sometimes make my own } \\
\text { adjustments when I forget to } \\
\text { take my medicine or take the } \\
\text { wrong one }\end{array}$ & $\begin{array}{l}\text { If I forget to take my medicine } \\
\text { or take the wrong one, I make } \\
\text { adjustments within the limit } \\
\text { prescribed by my doctor }\end{array}$ & (No revision) \\
\hline & (10) & $\begin{array}{l}\text { I do not tell my medical staff } \\
\text { about changes in the dosage } \\
\text { or type of medicine I am taking, } \\
\text { or if I have stopped taking it }\end{array}$ & $\begin{array}{l}\text { I make sure to ask my medical } \\
\text { professionals if I want to (or } \\
\text { intend to) change the dosage } \\
\text { or type of medicine or } \\
\text { stop taking it }\end{array}$ & (No revision) \\
\hline
\end{tabular}




\begin{tabular}{|c|c|c|c|c|}
\hline \multirow{6}{*}{ 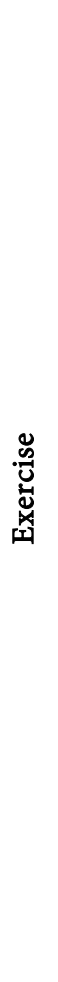 } & (11) & I do not exercise continuously & $\begin{array}{l}\text { I habitually do exercise } \\
\text { that is suitable for me }\end{array}$ & (No revision) \\
\hline & (12) & $\begin{array}{l}\text { I sometimes exercise but that } \\
\text { puts stress on my body } \\
\text { (especially my abdomen) }\end{array}$ & $\begin{array}{l}\text { I avoid exercise that would } \\
\text { put pressure on the } \\
\text { transplanted kidney }\end{array}$ & (No revision) \\
\hline & (13) & $\begin{array}{l}\text { I have not thought about } \\
\text { whether I have been able } \\
\text { to adequately exercise }\end{array}$ & $\begin{array}{l}\text { I adjust the amount of exercise } \\
\text { I do based on what I think is } \\
\text { appropriate for my body }\end{array}$ & (No revision) \\
\hline & (14) & $\begin{array}{l}\text { Even if I have a symptom that } \\
\text { prevents me from exercising, I } \\
\text { sometimes ignore it }\end{array}$ & $\begin{array}{l}\text { Regardless of the transplant, if I } \\
\text { cannot continue exercising } \\
\text { for any reason, I would not } \\
\text { ignore it and consult my } \\
\text { medical professionals }\end{array}$ & $\begin{array}{l}\text { If I cannot continue exercising } \\
\text { for some reason, even if it is } \\
\text { unrelated to the } \\
\text { transplantation, I would not } \\
\text { ignore it and consult my } \\
\text { medical professionals }\end{array}$ \\
\hline & (15) & $\begin{array}{l}\text { I sometimes exercise even when } \\
\text { I am not feeling quite right }\end{array}$ & $\begin{array}{l}\text { I do not force myself to } \\
\text { exercise when I am not } \\
\text { feeling quite right }\end{array}$ & (No revision) \\
\hline & (16) & $\begin{array}{l}\text { I do not regularly tell my } \\
\text { medical professionals or } \\
\text { consult them about the amount } \\
\text { or type of exercise I do }\end{array}$ & $\begin{array}{l}\text { I tell or consult my medical } \\
\text { staff regarding the amount } \\
\text { and type of exercise I do }\end{array}$ & (No revision) \\
\hline \multirow{7}{*}{ 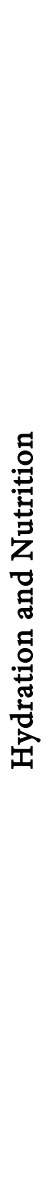 } & (17) & $\begin{array}{l}\text { Sometimes I do not consume } \\
\text { enough fluids }\end{array}$ & $\begin{array}{l}\text { Based on my medical staff's } \\
\text { prescription or advice, I } \\
\text { consume an appropriate } \\
\text { amount of fluids for the season }\end{array}$ & (No revision) \\
\hline & (18) & $\begin{array}{l}\text { I often have opportunities } \\
\text { to eat heavily seasoned food }\end{array}$ & $\begin{array}{l}\text { Based on my medical staff's } \\
\text { prescription or advice, I } \\
\text { moderate my intake of } \\
\text { salty foods }\end{array}$ & (No revision) \\
\hline & (19) & $\begin{array}{l}\text { Sometimes I consume too } \\
\text { much sodium or protein }\end{array}$ & $\begin{array}{l}\text { Based on my medical staff's } \\
\text { prescription or advice, I } \\
\text { consume an appropriate } \\
\text { amount of protein }\end{array}$ & (No revision) \\
\hline & (20) & $\begin{array}{l}\text { I often have opportunities to } \\
\text { drink alcohol or sometimes } \\
\text { drink too much }\end{array}$ & $\begin{array}{l}\text { I avoid alcohol as much as } \\
\text { possible, and make it a point } \\
\text { not to drink too much even if I } \\
\text { have opportunities to drink }\end{array}$ & $\begin{array}{l}\text { When drinking alcohol, I set a } \\
\text { rough limit and do not exceed it } \\
\text { (or I do not drink alcohol) }\end{array}$ \\
\hline & $(21)$ & $\begin{array}{l}\text { I often have opportunities to eat } \\
\text { out or eat convenience store } \\
\text { food }\end{array}$ & $\begin{array}{l}\text { When eating out or eating } \\
\text { convenience store food, I pay } \\
\text { attention to the nutrition labels }\end{array}$ & (No revision) \\
\hline & (22) & $\begin{array}{l}\text { I often have opportunities to eat } \\
\text { processed foods }\end{array}$ & $\begin{array}{l}\text { I try to avoid consuming } \\
\text { processed foods or foods with } \\
\text { additives as much as possible }\end{array}$ & (No revision) \\
\hline & (23) & $\begin{array}{l}\text { I sometimes adjust my diet and } \\
\text { alcohol intake in advance of } \\
\text { medical examinations }\end{array}$ & $\begin{array}{l}\text { I do not adjust my diet or } \\
\text { alcohol intake in advance } \\
\text { of medical examinations }\end{array}$ & $\begin{array}{l}\text { I do not adjust my diet or } \\
\text { alcohol intake in advance of } \\
\text { medical examinations }\end{array}$ \\
\hline
\end{tabular}


(24) adjust my fluid intake when my urine volume decreases or I experience swelling

I do not reexamine my diet even

I have not confirmed whether anything is amiss in the transplanted area

I would not consult my medical staff if I experienced symptoms of organ rejection, such as onset of fever, decrease in urine, pain in the kidney transplant area, or high blood pressure

(30)

I often go to crowded or polluted places

I do not use a mask even during

(31) the epidemic of an infectious disease

I do not brush my teeth or sometimes forget to
I take the initiative to moderate my sodium intake or adjust my fluid intake when my urine volume decreases or I experience swelling

When I have eaten too much or eaten heavily seasoned food, I reexamine my diet so that it does not become a regular occurrence

I regularly tell my medical professionals or consult them about the type or amount of food I eat

I regularly weigh myself and take my blood pressure and body temperature

I am always paying attention to symptoms such as sudden weight gain, swelling, feelings of lethargy, fever, decrease in urine volume, bloody urine, changes in blood pressure, or discomfort around the transplanted kidney

I immediately tell my doctor if I experience symptoms such as sudden weight gain, swelling, feelings of lethargy, fever, decrease in urine volume, bloody urine, changes in blood pressure, or discomfort around the transplanted kidney

I avoid going to crowded or polluted places any more than necessary

I make sure to wear a mask and disinfect my hands during the epidemic of infectious diseases and when I go to crowded places

I brush my teeth every day without fail
I moderate my sodium intake or adjust my fluid intake when my urine volume decreases or I experience swelling

When I have eaten too much or eaten heavily seasoned food, I reexamine my diet so that it does not become a regular occurrence

(No revision)

(No revision)

I am attentive to symptoms such as sudden weight gain, swelling, feelings of lethargy, fever, decrease in urine volume, bloody urine, changes in blood pressure, or discomfort around the transplanted kidney

I consult my medical professionals if I experience symptoms such as sudden weight gain, swelling, feelings of lethargy, fever, decrease in urine volume, bloody urine, changes in blood pressure, or discomfort around the transplanted kidney

(No revision)

(No revision)

(No revision) 
(33)

I do not regularly go for dental check-ups

I do not regularly get examined

(34) for cancer, heart disease,

diabetes, etc.

(35)

I do not observe the volume or color of my urine

I would not do anything even if

(36) my blood test results indicated a problem

I would not get examined or

(38) consult with my medical professionals when I feel unwell

(39)

(40)

I do not get enough sleep or rest

泀
I sometimes ruminate about problems related to the transplant

I do not talk with family members or those close to

(42)
I would not consult my medical staff even if there was something I did not understand about the side effects of a medicine or post-transplantation complications
I regularly go for dental check-ups

I regularly get examined for

I observe the volume or color of my urine

If my blood test results indicated a problem, I would make changes in my lifestyle accordingly to alleviate it

When I feel unwell, I get examined or consult with my medical doctors right away and do not put it off

Sometimes I do not ask for clarification regarding a treatment, examination, or my medical staff's guidance or advice

I would consult my medical professionals if there was something I did not understand about the side effects of a medicine or post-transplantation complications cancer and heart disease

(No revision)

I regularly get examined to see if I have developed cancer or heart disease

I observe the volume or color of my urine myself at regular intervals

(No revision)

(No revision)

I ask for clarification if there is something I do not understand regarding a treatment, examination, or my doctor's guidance or advice

(No revision)

I am not being able to get the amount of sleep or rest that is adequate for me

(No revision)

I am coping well with how the transplantation has affected and changed me and my life

I am coping well (or can cope) with any changes that the transplant has caused in me personally or my life

If I feel anxiety about something related to the transplant, I discuss it with others, including my doctor
If I feel anxiety regarding the transplantation, I discuss it with others, including my doctor about something related to the transplant 
(43)

When I am stressed, I do not try to resolve it on my own or discuss it with anyone

I would not tell my medical
When I am stressed and cannot resolve it on my own, I discuss it with someone such as a family member, a friend, or my medical professionals

If I was uneasy or unhappy as a result of the transplantation, I would discuss it with someone such as a family member, a friend, or my medical professionals, and solve it
If I am stressed and cannot resolve it on my own, I would discuss it with someone such as a family member, a friend, or my doctor

If I was uneasy or unhappy as a result of the transplantation, I would discuss it with someone such as a family member, a friend, or my doctor

consensus methods.

The Delphi method is a technique to form a consensus by repeating the process of a) non-face-to-face discussion, b) exchange of opinions in anonymity, and c) "response-analysis-feedback-response" with participating experts. However, there is a possibility that issues are not considered from various points of view in the "non-face-to-face review," which is only an exchange of documents [12]. Therefore, in this study, the modified Delphi method [13] was adopted to conduct a "face-to-face examination" while satisfying the requirement of "maintaining anonymity in opinion aggregation".

4) Selection of experts

To examine the assessment tool from both treatment and care perspectives and ensure the reliability of the consensus, we included certified transplant recipient coordinators (RTCs), physicians, outpatient nurses, and researchers who are frequently involved in recipient follow-up and research.

a) Selection criteria

i) RTCs, physicians, and outpatient nurses

At least 3 years of experience in follow-up of post-renal transplant recipients

We are currently providing treatment and care related to kidney transplantation.

ii) Researchers

Experience in the follow-up of patients with renal failure, at least one paper on research related to renal failure, and a master's degree or higher

b) Target number of people

Previous studies have stated that a minimum of five experts is needed to avoid coincidence [14]. In this study, at least one RTC, a physician, an outpatient nurse, and a researcher were each included in the study, with no upper limit on the number of participants.

c) Request for cooperation from the subject

Members of the research group to which the researcher belongs and their referrals were asked to cooperate in this study. The request for cooperation was made by sending a letter and a research plan approved by the research ethics 
committee of the institution to which the principal investigator belongs by e-mail. If the consent of the candidate subject's institution was required, we sent a research explanation document to the head of the institution and obtained consent for research cooperation. The consent of the candidate subjects was determined by signing and returning the research cooperation consent form.

5) Procedures and analysis methods

We referred to the recommendation that the process of "response-analysisfeedback-response" should be repeated at least three times [15].

a) Round 1 (Questionnaire survey and face-to-face discussion)

i) Survey method

A questionnaire about the evaluation tool was sent to the panels who agreed to participate in this study. The questionnaires were sent to the participants who agreed to participate in this study by both mail and e-mail. This ensured that the participants could choose the easiest way to answer the questionnaire, either by handwriting or typing. We asked the participants to print out the survey form themselves and return it anonymously. However, if the subject did not wish to remain anonymous, he or she could return the questionnaire by e-mail. When the questionnaire was sent and returned by e-mail, a password set at the beginning of the study was applied.

The panels were asked to rate the "appropriateness" and "validity" of the items of the evaluation tool on a 10-point scale from " 0 : not at all appropriate/not at all relevant" to "9: sufficiently appropriate/sufficiently relevant". In addition, a comment column was provided for each item and the evaluation tool as a whole. The evaluation based on the experience and knowledge of the panels and the description of opinions were requested for the expression, content, and setting of the domain.

ii) Analysis and feedback of survey results

The rating by the panels to each item of the questionnaire was determined as follows: 0 to 3 points: not appropriate/not valid, 4 to 6 points: difficult to judge, 7 to 9 points: appropriate/valid). In the Delphi method, the median and interquartile range (hereafter referred to as IQR), not just the mean and standard deviation, are often used to aggregate opinions. However, it was inferred from experience that the IQR is an unfamiliar indicator for clinicians who do not specialize in research. Therefore, in order to make it easier for all panels to understand the position of their own evaluation of each item in the group, we calculated the median, IQR, and percentage of the number of people in the IQR (hereafter referred to as IQR\%), as well as the mean and the most frequent values of the evaluations of "appropriateness" and "validity," and provided feedback to the panels. The consensus criteria for "appropriateness" and "validity" were "a median score of 7 or more points, an IQR of 1 or less, and an IQR of $80 \%$ or more" [16] [17] [18] or "the minimum value of the evaluation by each collaborators was 7 or more", referring to previous studies.

Focusing on the items that did not reach the consensus standard among each 
item, we modified the expressions and revised the items based on the comments obtained from the panels. Following the modifications, we had them re-evaluated in the next step of the survey. During the feedback, responses to all the comments were prepared so that the intention of the questions in each item and the intention of the revision of each item could be understood by the panels.

b) Face-to-face review ("meeting")

The "Results of the analysis of the responses to the questionnaire survey," "Responses to comments from panels," and "Proposed revisions to each item" were organized and sent to the participants at least one week before the faceto-face discussion. On the day of the meeting, these contents were used as a reference for discussion with the panels. The content of the meeting was recorded with prior consent so that it could be confirmed at a later date.

In meetings, there are concerns about the time/monetary cost for participants to assemble and the influence on discussions due to relationships among participants. Therefore, in this study, the following conditions were set: 1) a free online tool was used, 2) each participant changed his or her name to a pre-assigned number at the start of the meeting, and 3) all participants except the principal investigator participated only by voice without using the camera function. In addition, the face-to-face discussion time was set at about 60 minutes in consideration of the time burden on the subject. If there were too many participants, we divided them into groups of about five and held several meetings to have active discussions. In such cases, feedback was given in the next round so that all panels could share the contents of discussions in other meetings.

c) Modification of the questionnaire

Based on the results of the analysis of the questionnaire survey and the discussion in the meeting, the questionnaire was revised. Even for items for which a consensus was reached once, it was decided to ask the respondents to answer again in the following survey. This was because the answers might change depending on the relationship with the revised items or reconsideration by the experts. In addition, the wording of the items was modified to reflect the comments of the panels as much as possible, regardless of whether consensus was reached or not.

d) Round 2/Round 3 (Questionnaire survey)

i) Questionnaire survey

In the second round, we also sent the "responses to the comments from the cooperators at the meeting" to the participants similar to the previous round. In the second round, "responses to comments from panels at the meeting" were also sent. The method of responding to the modified questionnaire was the same as in the previous round.

ii) Analysis and revision of responses to the questionnaire survey

The second round of analysis was conducted similar to the previous round. In the third round of analysis, the item-level content validity index (I-CVI) was used in addition to the minimum, median, IQR, and IQR\% [14] [19], and the consensus criterion was the same as in the first and second rounds and I-CVI 
0.80 or higher. The consensus criterion was the same as in rounds 1 and 2 and I-CVI 0.80 or higher. The I-CVI was calculated based on the number of items for which the validity evaluation by each expert was "7" or more out of 9 levels.

In addition, even if the items were above the consensus standard or if the comments or suggestions for revision were presented at the time of evaluation, they were revised.

\section{Survey Period}

The three-stage modified Delphi study was conducted between January and May 2020.

\section{Ethical Considerations}

In order to protect the rights of the panels, we explained in the research instructions the purpose of the study, the method of the modified Delphi method, that participation in the study was based on free will, consent could be withdrawn at any point during the study period without any disadvantage to the subjects, and that anonymity would be ensured when the study results were published.

This study was conducted with the approval of the Research Ethics Committee of Osaka Medical and Pharmaceutical University (2020-121).

\section{Results}

1) Characteristics of panels

Table 2 shows the characteristics of the panels and the number of panels for each round.

We obtained the cooperation of 17 experts (10 RTCs, 3 physicians, 2 outpatient nurses, and 2 researchers) from 15 facilities in 5 of the 7 provinces in Japan. Three of them were unable to cooperate in the meetings due to work commitments, but all 17 responded to the first and third rounds of the questionnaire survey.

The years of clinical experience of the panels were RTCs: $22.1 \pm 5.9$ years, physicians: $34.1 \pm 9.2$ years, outpatient nurses: $19.8 \pm 7.5$ years, and researchers: $18.6 \pm 12.6$ years. The years of experience in follow-up of post-renal transplant

Table 2. Characteristics of the experts and the number of experts in each round.

\begin{tabular}{|c|c|c|c|c|c|c|c|c|c|}
\hline \multirow[b]{2}{*}{ Occupation } & \multirow{2}{*}{$\begin{array}{c}\text { Number } \\
\text { of } \\
\text { experts }\end{array}$} & \multirow{2}{*}{$\begin{array}{l}\text { Average years of } \\
\text { experience in } \\
\text { following up } \\
\text { with recipients }\end{array}$} & \multirow{2}{*}{$\begin{array}{l}\text { Average } \\
\text { years of } \\
\text { clinical } \\
\text { experience }\end{array}$} & \multicolumn{2}{|c|}{ Degree } & \multicolumn{4}{|c|}{ Round 2} \\
\hline & & & & Master's & Doctral & Round 1 & Meeting & Questionnaire & Round 3 \\
\hline RTC & 10 & $11.6 \pm 4.6$ & $22.1 \pm 5.9$ & 2 & 0 & 10 & 8 & 10 & 10 \\
\hline Physician & 3 & $25.4 \pm 9.7$ & $34.1 \pm 9.2$ & 0 & 1 & 3 & 2 & 3 & 3 \\
\hline $\begin{array}{l}\text { Outpatient } \\
\text { nurse }\end{array}$ & 2 & $8.8 \pm 1.8$ & $19.8 \pm 7.5$ & 1 & 0 & 2 & 2 & 2 & 2 \\
\hline Researcher & 2 & $7.5 \pm 1.5$ & $18.6 \pm 12.6$ & 1 & 1 & 2 & 2 & 2 & 2 \\
\hline
\end{tabular}


recipients were as follows: RTCs: $11.6 \pm 4.6$ years, physicians: $25.4 \pm 9.7$ years, outpatient nurses: $8.8 \pm 1.8$ years, and researchers: $7.5 \pm 1.5$ years. One physician had a doctorate and two RTCs and one outpatient nurse had master's degrees. One researcher had a master's degree and the other a doctorate.

2) Round 1 (Table 1, Table 3, Table 4)

The questionnaire items for the first round are shown in Table 1, and the survey results are shown in Table 3. The comments from each collaborator are shown in Table 4.

Of the 41 items in the 5 domains of the created assessment tool, only 14 items met the consensus criteria for both appropriateness and validity: 1 item in the medication domain (1), 2 items in the exercise domain $(12,13), 4$ items in the fluid and nutrition domain $(18,19,25,26)$, and 7 items in the disease and symptom prevention and management domain (27, 29, 32, 33, 34 and 36, 39). In particular, items 10 and 11 had an IQR of 3 or higher for both appropriateness and validity.

The six items with significantly lower IQR\% of appropriateness or adequacy $(<50 \%)$ were $13,14,17,27,43$, and 44 . A total of 90 comments were obtained from panels for each item ( 25 in the medication domain, 27 in the exercise domain, 15 in the fluid and nutrition domain, 19 in the disease and symptom management and prevention domain, and 4 in the psychosocial adjustment domain) (Table 4).

These results were then fed back to the panels and discussed in meetings. Table 5 shows the outline of the meeting. In order to expect an active exchange of opinions at the meetings, the panels were divided into three groups, and the meetings were held three times (Table 5).

The items were then revised based on the results of the questionnaire survey and meetings. Item 4, "I sometimes run out of stock of the medicine," was divided into two items: Item 5, "I always keep the stock of the medicine for two weeks on hand just in case," and Item 6: "I have not kept medicine that I forgot to take as extras (stock) without my doctor's permission".

In addition, in response to the comments, we newly added item 38, "Sometimes I do not ask for clarification regarding a treatment, examination, or my medical staff's guidance or advice."

In this study, we thought that respondents might unconsciously give high ratings to items with the expression "I am able to do it" and that it might be difficult to derive accurate answers, so we used the expression "I am not able to do it" frequently in the original proposal. However, we received opinions from several experts that questions based on the assumption that the respondent is not able to self-manage may damage the recipient's self-esteem. Furthermore, in the second stage, we revised many of the question items to positive questions similar to those in previous studies.

3) Round 2 (Questionnaire survey) (Table 1, Table 3, Table 4)

The questionnaire items for the second round are shown in Table 1, and the survey results are shown in Table 3. The comments from each panel are also 
Table 3. Results of each round.

\begin{tabular}{|c|c|c|c|c|c|c|c|c|c|c|c|c|c|c|c|c|c|c|c|c|c|c|c|c|c|c|}
\hline \multirow{3}{*}{ 总 I } & \multirow{3}{*}{ Item } & \multicolumn{8}{|c|}{ Round 1} & \multicolumn{8}{|c|}{ Round 2} & \multicolumn{9}{|c|}{ Round 3} \\
\hline & & \multicolumn{4}{|c|}{ Appropriateness } & \multicolumn{4}{|c|}{ Validity } & \multicolumn{5}{|c|}{ Appropriateness } & \multicolumn{3}{|c|}{ Validity } & \multicolumn{4}{|c|}{ Appropriateness } & \multicolumn{5}{|c|}{ Validity } \\
\hline & & MIN & $\mathbf{M}$ & IQR & $\begin{array}{c}\text { IQR } \\
\%\end{array}$ & MIN & $\mathbf{M}$ & IQR & $\begin{array}{c}\text { IQR } \\
\%\end{array}$ & MIN & M & IQR & $\begin{array}{c}\text { IQR } \\
\%\end{array}$ & MIN & $\mathbf{M}$ & IQR & $\begin{array}{c}\text { IQR } \\
\%\end{array}$ & MIN & M & IQR & $\begin{array}{c}\text { IQR } \\
\%\end{array}$ & MIN & $\mathbf{M}$ & $\mathrm{IQR}$ & $\begin{array}{c}\text { IQR } \\
\%\end{array}$ & ICVI \\
\hline \multirow{10}{*}{$\Sigma$} & (1) & 6 & 9 & 1 & 94.1 & 7 & 9 & 1 & 100 & 3 & 8 & 1 & 82.4 & 3 & 9 & 1 & 82.4 & 8 & 9 & 0.5 & 76.5 & 7 & 9 & 0.5 & 76.5 & 1 \\
\hline & (2) & 6 & 8 & 2 & 64.7 & 6 & 8 & 2 & 70.6 & 5 & 8 & 1 & 82.4 & 5 & 8 & 1 & 82.4 & 7 & 9 & 1 & 82.4 & 7 & 9 & 1.5 & 76.5 & 1 \\
\hline & (3) & 6 & 9 & 1.5 & 94.1 & 6 & 9 & 1 & 94.1 & 6 & 8 & 2 & 81.3 & 6 & 8 & 2 & 81.3 & 7 & 9 & 0.5 & 76.5 & 7 & 9 & 0.5 & 76.5 & 1 \\
\hline & (4) & 5 & 8 & 2 & 64.7 & 5 & 8 & 2 & 64.7 & - & - & - & - & - & - & - & - & - & - & - & - & - & - & - & - & - \\
\hline & (5) & - & - & - & - & - & - & - & - & 6 & 8 & 1.5 & 76.5 & 6 & 8 & 1.5 & 76.5 & 7 & 9 & 1 & 82.4 & 6 & 9 & 1 & 82.4 & 0.941 \\
\hline & (6) & - & - & - & - & - & - & - & - & 5 & 8 & 1.75 & 62.5 & 5 & 8 & 1.75 & 68.8 & 5 & 8 & 2 & 94.1 & 5 & 8 & 1 & 82.4 & 0.882 \\
\hline & (7) & 2 & 8 & 1.5 & 88.2 & 2 & 8 & 1 & 88.2 & 7 & 9 & 1 & 94.1 & 7 & 9 & 1 & 94.1 & 8 & 9 & 0 & 82.4 & 8 & 9 & 0 & 82.4 & 1 \\
\hline & (8) & 7 & 8 & 1.5 & 58.8 & 7 & 8 & 1 & 58.8 & 7 & 9 & 1 & 94.1 & 7 & 9 & 1 & 94.1 & 8 & 9 & 0.5 & 76.5 & 8 & 9 & 0.5 & 76.5 & 1 \\
\hline & (9) & 6 & 9 & 2 & 70.6 & 6 & 9 & 1.5 & 76.5 & 7 & 9 & 1 & 94.1 & 7 & 9 & 1 & 94.1 & 7 & 9 & 1 & 94.1 & 7 & 9 & 1 & 94.1 & 1 \\
\hline & (10) & 0 & 8 & 3.5 & 64.7 & 2 & 8 & 3.5 & 64.7 & 7 & 9 & 1 & 88.2 & 7 & 9 & 1 & 88.2 & 5 & 9 & 1 & 94.1 & 5 & 9 & 1 & 94.1 & 0.941 \\
\hline \multirow{6}{*}{ แै } & (11) & 3 & 7 & 3 & 76.5 & 3 & 7 & 3 & 76.5 & 5 & 9 & 1 & 82.4 & 5 & 9 & 1 & 88.2 & 7 & 9 & 1 & 94.1 & 7 & 9 & 1 & 88.2 & 1 \\
\hline & (12) & 5 & 7 & 0.5 & 82.4 & 5 & 7 & 1 & 82.4 & 5 & 8 & 1 & 82.4 & 5 & 8 & 1 & 88.2 & 7 & 9 & 1 & 82.4 & 7 & 9 & 1.5 & 76.5 & 1 \\
\hline & (13) & 2 & 7 & 1 & 41.2 & 2 & 8 & 2 & 58.8 & 7 & 8 & 1 & 88.2 & 7 & 8 & 1 & 88.2 & 7 & 9 & 1 & 82.4 & 7 & 9 & 1 & 88.2 & 1 \\
\hline & (14) & 3 & 7 & 2 & 41.2 & 3 & 7 & 1.5 & 82.4 & 6 & 8 & 1 & 82.4 & 6 & 8 & 1 & 82.4 & 6 & 9 & 1 & 88.2 & 6 & 9 & 1 & 88.2 & 0.941 \\
\hline & (15) & 5 & 8 & 2 & 64.7 & 5 & 7 & 1.5 & 70.6 & 5 & 8 & 1 & 88.2 & 5 & 8 & 1 & 88.2 & 7 & 9 & 1 & 82.4 & 7 & 9 & 1 & 87.5 & 0.941 \\
\hline & (16) & 4 & 7 & 2 & 70.6 & 4 & 7 & 1 & 64.7 & 7 & 8 & 1 & 88.2 & 7 & 8 & 1 & 88.2 & 7 & 9 & 1 & 88.2 & 7 & 9 & 1 & 87.5 & 0.941 \\
\hline \multirow{10}{*}{ 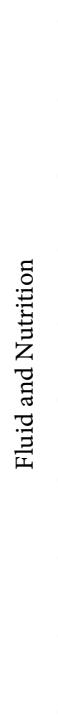 } & (17) & 5 & 9 & 1 & 35.3 & 6 & 9 & 1 & 29.4 & 7 & 9 & 1 & 94.1 & 7 & 9 & 1 & 94.1 & 8 & 9 & 1 & 100 & 7 & 9 & 0.75 & 75 & 0.941 \\
\hline & (18) & 5 & 8 & 1 & 88.2 & 7 & 8 & 1 & 94.1 & 7 & 9 & 1 & 94.1 & 7 & 9 & 1 & 94.1 & 8 & 9 & 0.5 & 76.5 & 8 & 9 & 0.75 & 75 & 0.941 \\
\hline & (19) & 5 & 9 & 1 & 82.4 & 7 & 8 & 1 & 88.2 & 6 & 8 & 1 & 88.2 & 6 & 8 & 1 & 88.2 & 7 & 9 & 1 & 94.1 & 7 & 9 & 1 & 93.8 & 0.941 \\
\hline & (20) & 5 & 8 & 2 & 70.6 & 6 & 8 & 2 & 70.6 & 6 & 8 & 1.5 & 76.5 & 6 & 8 & 1.5 & 76.5 & 7 & 8 & 1 & 82.4 & 7 & 8 & 2 & 100 & 0.941 \\
\hline & (21) & 5 & 8 & 2 & 88.2 & 6 & 8 & 2 & 88.2 & 5 & 8 & 1 & 88.2 & 5 & 8 & 1 & 88.2 & 7 & 9 & 1 & 94.1 & 7 & 9 & 1 & 87.5 & 0.941 \\
\hline & (22) & 5 & 8 & 2 & 88.2 & 6 & 8 & 2 & 88.2 & 6 & 8 & 2 & 88.2 & 6 & 8 & 2 & 88.2 & 6 & 9 & 1.5 & 76.5 & 6 & 9 & 1 & 81.3 & 0.882 \\
\hline & (23) & 6 & 8 & 1.5 & 94.1 & 6 & 8 & 1.5 & 94.1 & 7 & 8 & 1.5 & 76.5 & 7 & 8 & 1.5 & 76.5 & 7 & 8 & 1.5 & 76.5 & 7 & 8 & 1 & 81.3 & 0.941 \\
\hline & (24) & 4 & 8 & 1.5 & 64.7 & 4 & 8 & 2 & 70.6 & 5 & 8 & 1 & 88.2 & 5 & 8 & 1 & 88.2 & 7 & 9 & 1 & 82.4 & 7 & 8.5 & 1 & 81.3 & 0.941 \\
\hline & (25) & 7 & 8 & 1 & 58.8 & 7 & 8 & 1 & 100 & 7 & 9 & 1 & 94.1 & 7 & 8 & 1 & 94.1 & 7 & 9 & 1 & 94.1 & 7 & 9 & 1 & 93.8 & 0.941 \\
\hline & (26) & 7 & 8 & 1.5 & 70.6 & 7 & 8 & 1 & 82.4 & 6 & 8 & 1 & 82.4 & 6 & 8 & 1 & 82.4 & 7 & 9 & 1 & 94.1 & 7 & 9 & 1 & 87.5 & 0.941 \\
\hline
\end{tabular}


Continued

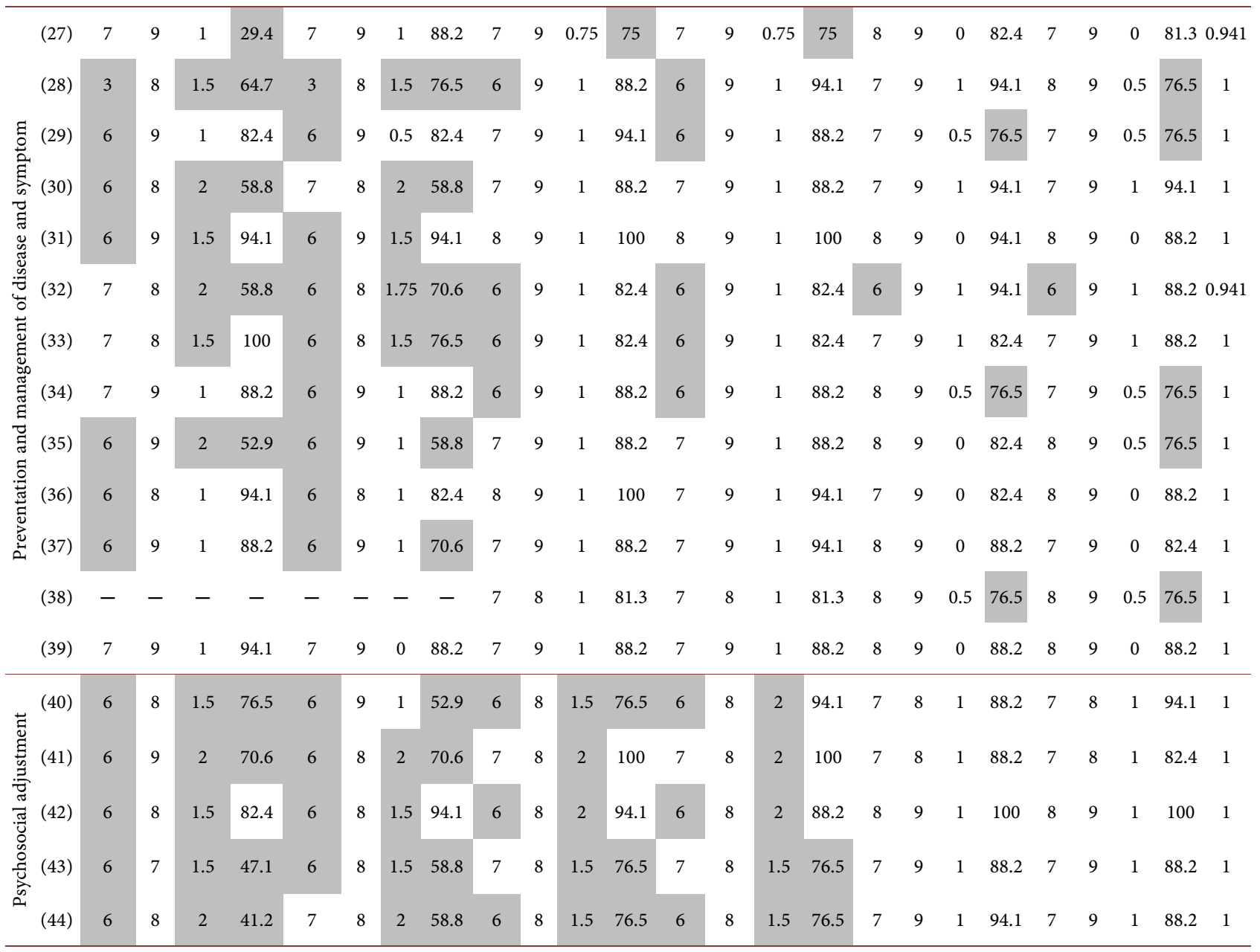

Abbreviations: MIN, minimum; M, median; IQR, interquartile range; IQR\%, percentage of people in the interquartile range; I-CVI, Item-level content validity index. Notes: "-" indicates no item for that round. A filled frame indicates that the item does not meet the consensus criteria. (Consensus criteria: MIN $\geq 7, \mathrm{M} \geq 7, \mathrm{IQR} \geq 1, \mathrm{IQR} \% \geq 80$, I-CVI $\geq 0.9$ ).

shown in Table 4.

Of the 43 items in the 5 domains of the questionnaire, 7 items in the medication domain $(1,2,7,8,9,10,11), 5$ items in the exercise domain $(11,13,14,15$, $16), 8$ items in the fluid and nutrition domain $(17,18,19,21,2324,25$, and 26), a total of 13 items in the disease/symptom prevention and management domain, and 2 items in the psychosocial adaptation domain (41 and 43), for a total of 35 items, no item had an IQR of more than 2 for either appropriateness or adequacy. Additionally, no item had a significantly low IQR\% $(<50 \%)$ for either. Therefore, we did not delete any items that did not meet the consensus criteria in this round.

A total of 40 comments were obtained from panels on the items (14 on medication, 3 on exercise, 9 on diet, 9 on prevention, and 5 on psychosocial) (Table 4). Regarding the questionnaire as a whole, comments were obtained that "the questionnaire items were revised based on everyone's opinions, and there were no more items that were difficult to answer" and "the questionnaire was easier to 
Table 4. Panel's comments from each round.

$\begin{array}{lc}\text { Field } \quad \text { Round } 1 \text { comments }(90 \text { comments }) & \text { Round } 2 \\ & \text { comments } \\ (40 \text { comments })\end{array}$

(2): Depends on how much it deviates.

(3): If it's once in a blue moon, that can't be helped

(4): It is advised to have stock for two weeks for disaster situations. It would be better to include the phrase

"for two weeks."

(4): Having too much "stock" left over isn't a good thing either. It is necessary to distinguish between medicine you forgot to take and excess medicine.

(7): How should someone answer if they never forget to take their medicine?

(9): If someone makes adjustments in the prescribed time range, I don't think that's a problem

\section{(2): Would}

"within 2 hours" be okay?

(5): I don't think there's any need to specify "two weeks"

(6): I'd rather they save it than throwing it out
Round 3 comments (15 comments)

(1)-(3): Is there no need to distinguish between immunosuppressants and other medicines?

(1)-(3): Is there no need to limit it to immunosuppresants?

(5): Not every region or hospital instructs people to keep " 2 weeks worth" of stock

(6): I don't understand what this question is getting at

(10): Respondents do not adjust their own immunosuppresant dosage, so I don't understand the point of asking this

(13): Even if the respondent answers that they "can," they might in fact be doing exercise that stresses the transplanted kidney. Should we consider this as a tool by which we can assess the discrepancy between their answer and the reality?

(14): It would be better for each respondent to judge for themselves whether this is something they should consult their doctor about in transplantation outpatient care (15): Simple present is better than present progressive tense here
(17), (18), (19), (20), (21), (22): It would be better to have prompts that ask how the person deals with it if they engage in such-and-such behavior

(17): Protecting a transplanted kidney requires more fluids than just enough to prevent dehydration

(17): The standard for "enough" varies depending on the facility. Certain facilities also prioritize different things, like measurement at regular intervals or total volume (of urine). It might be best to use the phrase "as instructed," as well. (18), (19): There are overlapping items regarding sodium (19): Requirements for adequate protein intake vary based on how long it has been since the transplantation. As such, it is better to avoid asking about it in the same prompt as sodium. (20): Drinking too much is to be cautioned against, but a small amount on occasion can't be helped

(21): Even restaurants and convenience stores have healthy items. It might be necessary to have a prompt that asks whether the person makes sure to know what is in the food they eat

(22): Attention must also be paid to additives
(21): The word

"paying

attention"

presents the

person with

another

hurdle in

self-management;

"confirm"

would be better
(23): Depends on if they answer honestly (26): They don't necessarily have to tell their doctor 


\section{Continued}

(28): Wouldn't

asking

respondents if

they "always"

do this result in

lower scores?

(37): As a health

management

strategy, I'm not

too sure about

asking your

doctor

immediately

just because a

symptom

occurred once

(35): Wouldn't

any respondent

who see this

prompt think

"So I have to

measure the color

and volume of my

urine every day?"

(42), (43), (44):

Should we

encourage them

to go as far as to

"resolve" it or

is it enough for

them talk to

someone about it?

Table 5. Overview of the face-to-face review (meeting).

\begin{tabular}{cccc}
\hline & Group A & Group B & Group C \\
\hline Number of experts & 7 & 3 & 4 \\
Meeting time (minutes) & 105 & 111 & 74 \\
\hline
\end{tabular}

answer than the previous one. The wording of 18 items was revised based on these results.

4) Round 3 (Questionnaire survey) (Table 1, Table 3, Table 4)

The questionnaire items for the third round are shown in Table 1, and the survey results are shown in Table 3. The comments from each panel are also shown in Table 4.

Of the 43 items in the five domains that were revised based on the results of the second round, the two items that did not meet the consensus standard in 
terms of both appropriateness and validity were item 6, "I have not kept medicine that I forgot to take as extras (stock), nor thrown it out, without my doctor's permission," and item 22, "I try to avoid consuming processed foods or foods with additives as much as possible." As for the other items, 25 items had an I-CVI of 1.0, and the remaining 16 items had an I-CVI of 0.80 or higher, meeting the consensus standard. Therefore, it was decided to adopt these 41 items as the items of the assessment tool.

A total of 15 comments were received from panels in Round 3 ( 7 medication, 3 exercise, 2 diet, 2 prevention, and 1 psychosocial). Since the third round was the final stage, the wording was modified with a comprehensive reference to the comments from the first three stages. Table 6 shows the final items.

\section{Discussion}

Previous studies have pointed out that a panel consisting of professionals from different geographical locations and specialties can produce good results [20] [21]. In this study, we were able to survey with the cooperation of 17 RTCs, physicians, outpatient nurses, and researchers from 15 facilities in 5 regions in Japan. This was sufficient to create a tool that reflected various viewpoints without being biased by the characteristics of regions, facilities, or professions. In addition, although previous studies have suggested that the response rate for each round of the Delphi survey should be 70\% [16]. The response rate for the three rounds of the questionnaire survey in this study was $100 \%$, and the three face-to-face surveys, in which 14 out of 17 participants cooperated, were conducted with the consent of the participants. Additionally, active discussions were held beyond the scheduled time of 60 minutes. In the three face-to-face surveys, 14 out of 17 respondents cooperated, and the discussions went beyond the scheduled 60 minutes with the consent of the respondents. Many comments on the questionnaires and suggestions for modifications and additions to the questionnaire items were obtained. Indicatively, many of the cooperators understood the importance of this study and actively examined the appropriateness and validity of each questionnaire item. The questionnaires were reviewed by professionals with an average of more than 15 years of clinical experience and an average of more than 5 years of recipient follow-up experience. In addition, each professional included at least one expert with a master's degree or higher, ensuring the reliability of the study results, which were based on a consensus of experts suitable for examining the self-management assessment items for postrenal transplant recipients.

The self-management of post-renal transplant recipients assessed in this tool covers five domains: medication, exercise, fluids and nutrition, disease and symptom prevention and management, and psychosocial adjustment, and is based on the KDIGO Clinical Practice Guideline for the Care of Kidney. The guideline covers five areas of self-management after kidney transplantation, including immunosuppressive therapy, monitoring of transplant kidney function, prevention 
Table 6. Final items on the self-management behavior scale for kidney transplant recipients.

\begin{tabular}{|c|c|c|c|c|c|}
\hline Field & $\begin{array}{l}\text { Item } \\
\text { number }\end{array}$ & Assessment item & Field & $\begin{array}{l}\text { Item } \\
\text { number }\end{array}$ & Assessment item \\
\hline \multirow{8}{*}{$\overbrace{\substack{0 \\
:}}^{0}$} & $(1)$ & $\begin{array}{l}\text { I never take more (or less) than the } \\
\text { prescribed dose of immunosuppressive } \\
\text { drugs or any other medicine }\end{array}$ & & $(27)$ & $\begin{array}{l}\text { I regularly weigh myself and take my } \\
\text { blood pressure and body temperature }\end{array}$ \\
\hline & $(2)$ & $\begin{array}{l}\text { I never deviate from the prescribed } \\
\text { time by at least } 2 \text { hours when taking } \\
\text { immunosuppressive drugs or any } \\
\text { other medicine }\end{array}$ & & ${ }^{*}(28)$ & $\begin{array}{l}\text { I am on the lookout for symptoms such } \\
\text { as sudden weight gain, swelling, feelings } \\
\text { of lethargy, fever, decrease in urine } \\
\text { volume, bloody urine, changes in blood } \\
\text { pressure, or discomfort around the } \\
\text { transplanted kidney }\end{array}$ \\
\hline & (3) & $\begin{array}{l}\text { I never forget to take my medicine, } \\
\text { be it an immunosuppressive drug } \\
\text { or any other medicine }\end{array}$ & & $(29)$ & $\begin{array}{l}\text { I consult my medical professionals if I } \\
\text { experience symptoms such as sudden } \\
\text { weight gain, swelling, feelings of } \\
\text { lethargy, fever, decrease in urine } \\
\text { volume, bloody urine, changes in blood } \\
\text { pressure, or discomfort around the } \\
\text { transplanted kidney }\end{array}$ \\
\hline & $\star(5)$ & $\begin{array}{l}\text { I always keep a stock of medicine } \\
\text { on hand just in case }\end{array}$ & & (30) & $\begin{array}{l}\text { I avoid going to crowded or polluted } \\
\text { places any more than necessary }\end{array}$ \\
\hline & (7) & $\begin{array}{l}\text { I have thought of a way to prevent } \\
\text { forgetting to take my medicine or } \\
\text { taking the wrong one } \\
\text { (or I never forget to take it) }\end{array}$ & 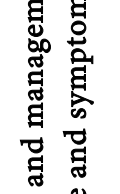 & $(31)$ & $\begin{array}{l}\text { I make sure to wear a mask and } \\
\text { disinfect my hands during the } \\
\text { epidemic of infectious diseases and } \\
\text { when I go to crowded places }\end{array}$ \\
\hline & $(8)$ & $\begin{array}{l}\text { I make sure to ask my medical } \\
\text { professionals if there is anything } \\
\text { regarding my medicine that I am } \\
\text { not sure about or have a trouble }\end{array}$ & 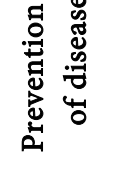 & $(32)$ & I brush my teeth every day without fail \\
\hline & (9) & $\begin{array}{l}\text { If I forget to take my medicine or take } \\
\text { the wrong one, I make adjustments } \\
\text { within the limit prescribed by my doctor }\end{array}$ & & $(33)$ & I regularly go for dental check-ups \\
\hline & $(10)$ & $\begin{array}{l}\text { I make sure to ask my medical } \\
\text { professionals if I want to (or intend to) } \\
\text { change the dosage or type of } \\
\text { medicine or stop taking it }\end{array}$ & & $(34)$ & $\begin{array}{l}\text { I regularly get examined to see if I } \\
\text { have developed cancer or heart disease }\end{array}$ \\
\hline \multirow{3}{*}{ 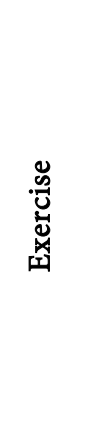 } & $(11)$ & $\begin{array}{l}\text { I habitually do exercise that is } \\
\text { suitable for me }\end{array}$ & & $(35)$ & $\begin{array}{l}\text { I observe the volume or color of my } \\
\text { urine myself at regular intervals }\end{array}$ \\
\hline & $(12)$ & $\begin{array}{l}\text { I avoid exercise that would put } \\
\text { pressure on the transplanted kidney }\end{array}$ & & $(36)$ & $\begin{array}{l}\text { If my blood test results indicated a } \\
\text { problem, I would make changes in my } \\
\text { lifestyle accordingly to alleviate it }\end{array}$ \\
\hline & (13) & $\begin{array}{l}\text { I adjust the amount of exercise I do } \\
\text { based on what I think is } \\
\text { appropriate for my body }\end{array}$ & & $(37)$ & $\begin{array}{l}\text { When I feel unwell, I get examined } \\
\text { or consult with my medical doctors } \\
\text { right away and do not put it off }\end{array}$ \\
\hline
\end{tabular}


(14) reason, even if it is unrelated to the transplantation, I would not ignore it and consult my medical professionals

I do not force myself to exercise when I am not feeling quite right

I tell or consult my medical staff

(16) regarding the amount and type of exercise I do

Based on my medical staff's prescription or advice, I consume an appropriate amount of fluids for the season

Based on my medical staff's

(18) prescription or advice, I moderate my intake of salty foods

Based on my medical staff's prescription or advice, I consume an appropriate amount of protein

When drinking alcohol, I set a rough limit and do not exceed it (or I do not drink alcohol)

When eating out or eating convenience store food, I pay

attention to the nutrition labels

I do not adjust my diet or alcohol intake in advance of medical examinations

I moderate my sodium intake or adjust my fluid intake when my urine volume decreases or I experience swelling

When I have eaten too much or eaten heavily seasoned food, I reexamine my diet so that it does not become a regular occurrence

I regularly tell my medical professionals or consult them about the type or amount of food I eat
I ask for clarification if there is something I do not understand regarding a treatment, examination, or my doctor's guidance or advice

I would consult my medical professionals if there was something I did not understand about the side effects of a medicine or post-transplantation complications

I am not being able to get the amount of sleep or rest that is adequate for me

I am coping well (or can cope) with any changes that the transplant has caused in me personally or my life

If I feel anxiety regarding the transplantation, I discuss it with others, including my doctor

If I am stressed and cannot resolve it on my own, I would discuss it with someone such as a family member, a friend, or my doctor

If I was uneasy or unhappy as a result of the transplantation, I would discuss it with someone such as a family member, a friend, or my doctor

Notes: ${ }^{\star}$ indicates items whose phrasing (in Japanese) was revised after Round 3. 
of infection, prevention and management of post-transplant diabetes and cardiovascular disease, lifestyle, and mental health [11].

The items in this tool are not just questions about whether or not the patient exercises or consumes alcohol. The content includes the recipient's perspective on daily life, which is necessary for improving the appropriateness of self-management and support for medical treatment [22]. As a result, it will be possible to assess the behaviors that recipients are prone to in their daily lives after kidney transplantation. Moreover, medical professionals will be able to consider what follow-up is necessary based on a more concrete understanding of the status of self-management in each area by recipients.

In the first round of the survey for this study, there were many comments about questions regarding the wording of the questions, modifications to the wording, and negative questions based on the assumption that self-management was not being done. In addition, some comments did not consider the item "I sometimes exercise even when I am not feeling quite right" as self-management, and there were comments that doubted the necessity of exercise after kidney transplantation in 5 of the 6 questions in the exercise area. As a result, many questions were not answered and may not have met the consensus criteria in this round. However, many of the items did meet the consensus in the Round 2 survey. The reason for this is that in the face-to-face meeting in the first round of the survey, the researcher and the collaborators who developed the questionnaire had an opportunity to directly confirm each other's ideas. In addition to the statistical data, comments from the panels obtained from the questionnaire survey and face-to-face meetings, and responses from the researcher to the comments were reported to all panels.

When providing feedback to panels, it may be difficult to convey the intentions of those who created and revised the questionnaire items if only statistical data are used to provide feedback after consensus. In addition, if the items that did not meet the consensus criteria and are deleted in early rounds in this situation, important items may be dropped out since it is difficult to consider all questionnaire items and derive a revised plan only in a face-to-face meeting with a time limit.

We believe that it is effective to provide qualitative data as well as feedback as in this study.

Non-adherence to immunosuppressive medication is an important issue for post-renal transplant recipients [23] [24]. In this study, we evaluated the Basel Assessment of Adherence to Immunosuppressive Medication Scale (BAASIS), which includes the following items: "missed dose," "multiple doses," "more than 2 hours before or after the indicated time," and "less than/more than the prescribed dose." [25] It is appropriate that the experts reached a consensus on the items corresponding to "consultation with medical personnel" to prevent selfjudgmental abstinence or withdrawal of medication [5], in addition to the items corresponding to "forgetting to take medication," "taking medication in multiple 
divided doses," "taking medication more than 2 hours before or after the time of instruction," and "taking medication more or less than the prescribed dose" of immunosuppressive drugs, [25] and the items on medication other than immunosuppressive drugs [22]. However, there was no consensus on the item "I have not kept medicine that I forgot to take as extras (stock), nor thrown it out, without my doctor's permission." This item, which asks whether or not the remaining medication is properly managed and is thought to have received a low rating because of the similarity in content with other items related to "forgetting to take medication" and "stocking." This could be a result of the intention of the question not being sufficiently conveyed.

All of the items in the exercise domain eventually met the consensus criteria. However, as mentioned earlier, in the first round, comments were questioning the necessity of exercise. Moreover, some comments did not consider unreasonable exercise during physical illness as an item for self-management. One of the reasons for this is that there is insufficient evidence for effective exercise therapy after kidney transplantation. However, since exercise therapy has been reported to improve exercise tolerance and prevent PTDM [26] [27], we believe it is important to adopt items to evaluate exercise after kidney transplantation as evaluation items for self-management after kidney transplantation.

In the diet and fluid area, we reached a consensus on 9 of the 10 behaviors that recipients are prone to, as reported in previous studies. We believe that these results are valid because diet and fluid management is important for preventing obesity, which is an important factor in cardiovascular disease and mortality, and for maintaining transplant kidney function.

However, no consensus was reached for the item "I try to avoid consuming processed foods or foods with additives as much as possible." Although we did not obtain any comments on the reason for this, referring to the comments on other items such as "sometimes it is somewhat unavoidable," we believe that the respondents judged that it is difficult to avoid such foods in daily life and that it is not feasible. In addition, there was a comment that wondered whether recipients would answer honestly to the item "I do not adjust the content and amount of food and alcohol consumed to coincide with the day of medical visits and examinations." For recipients who have been forced to follow a strict diet until transplantation, diet is one of their greatest pleasures, and restrictions on their favorite foods may be a factor in lowering their QOL. Therefore, it is necessary to evaluate the self-management of diet and fluids, especially in combination with the recipient's other behaviors and actions and not just the answers to the questions.

All items in the disease/symptom prevention and management area ultimately met the consensus criteria. In particular, it has been pointed out that poor oral hygiene increases the incidence of odontogenic infections and may lead to graft rejection. However, the low level of implementation of "brushing teeth to avoid damaging the oral mucosa" and "regular dental visits" has been reported [28] In 
addition, low implementation of other items, such as body temperature measurement, was also reported [28]. Therefore, we believe it was appropriate to obtain consensus on these items for evaluation. Contrarily, experts' opinions were divided on whether or not monitoring and medical visits should be conducted "every day" for some items. Of course, monitoring should ideally be performed daily, but there are no clear standards at this time, and decisions should be made on a case-by-case basis depending on the physical condition of the recipient. Therefore, it may be necessary to change the wording of the questions in this tool to "every day" or "once a week," depending on the physical condition of the recipient.

It has been reported that recipients continue to experience psychosocial stress after transplantation due to the time and financial burden of medical visits and testing, the constant threat of graft rejection, infection, and cancer development, and role limitations [29] [30] [31], and struggle to adjust to their current condition. However, support for self-management management focuses on improving medication adherence and self-monitoring [9] [10]. The expert consensus on the items in the psychosocial adjustment domain in this study indicates that they do not consider support for self-management in this domain to be unnecessary. Although it is practically difficult to assess psychosocial adjustment behaviors of all recipients on the spot and consider necessary support in a busy clinical setting, this tool may make it easier to assess and provide support to those recipients who need it.

In this study, we confirmed the content validity of a tool for assessing selfmanagement behaviors necessary for adult post-renal transplant recipients. In the future, we will survey the actual recipients using this tool and develop a tool that can be used in actual clinical practice after confirming its validity and reliability.

\section{Strength and Limitations}

In this study, we developed an assessment tool that can cover and evaluate a wide range of self-management behaviors. It includes behaviors that recipients tend to fall into and items that medical professionals overlook as necessary self-management after kidney transplantation. To the best of our knowledge, this is the first assessment tool that has achieved consensus among experts who actually conduct follow-up after kidney transplantation.

However, it is not realistic to include the full range of self-management behaviors necessary for post-renal transplant recipients in the items of this tool, and the items may be limited to those that are particularly representative. It is expected that assessment items will be added or modified in the future according to the environment surrounding the recipient and that the assessment tool will be brushed up. Therefore, it is necessary to evaluate self-management behaviors more deeply through dialogue with the recipient and evaluating using this tool as an entry point, rather than judging that there are no problems with self- 
management behaviors based solely on the evaluation of the items in this tool. In addition, it may be possible to learn more about the current state of self-management by finding discrepancies between the recipient's self-evaluation using this tool and actual behavior or blood data.

The items in this tool are based on a review of the literature for adult recipients. In addition, the expert panel is entirely Japanese and may not apply to underage recipients or in other regions.

\section{Conclusion}

A modified Delphi study identified 41 items needed to assess self-management behavior in adult post-renal transplant recipients with broad expert consensus on post-renal transplant follow-up. The self-management behavior scale for kidney transplant recipients assesses self-management behaviors in five domains: medication, exercise, fluids and diet, disease and symptom prevention and management, and psychosocial adjustment. This tool, which has been content-validated, has the potential to contribute to the maintenance of transplant kidney function and high QOL in recipients by making it easier to assess their selfmanagement behaviors in post-renal transplant follow-up.

\section{Acknowledgements}

We would like to extend our sincere gratitude to the experts who so graciously offered their valuable time to assist in our study and all who lent us their guidance along the way.

This study was conducted with the assistance of the JSPS Scientific Research Grant (JP18K17539).

This study is intended to be part of a dissertation for the Doctoral Program at the Osaka Medical and Pharmaceutical University Graduate School of Nursing.

\section{Conflicts of Interest}

There are no conflicts of interest related to this study.

\section{References}

[1] Levey, A.S., Eckardt, K.U., Tsukamoto, Y., et al. (2005) Definition and Classification of Chronic Kidney Disease: A Position Statement from Kidney Disease: Improving Global Outcomes (KDIGO). Kidney International, 67, 2089-2100.

[2] Murphy, F. (2007) The Role of Nurse Post-Renal Transplantation. British Journal of Nursing, 16, 667-675. https://doi.org/10.12968/bjon.2007.16.11.23689

[3] Barlow, J., Wright, C., Sheasby, J., Turner, A. and Hainsworth, J. (2002) Self-Management Approaches for People with Chronic Conditions: A Review. Patient Education and Counseling, 48, 177-187. https://doi.org/10.1016/S0738-3991(02)00032-0

[4] Wagner, E.H., Austin, B.T., Davis, C., Hindmarsh, M., Schaefer, J. and Bonomi, A. (2001) Improving Chronic Illness Care: Translating Evidence into Action. Health Affairs, 20, 64-78.

[5] Ndemera, H. and Bhengu, B.R. (2019) Engagement with Medication among Kidney 
Transplant Recipients-A Descriptive Cross-Sectional Study. Nephrology Nursing Journal: Journal of the American Nephrology Nurses' Association, 46, 49-57.

[6] Liu, H.X., Feurer, I.D., Dwyer, K., et al. (2009) Effects of Clinical Factors on Psychosocial Variables in Renal Transplant Recipients. Journal of Advanced Nursing, 65, 2585-2596. https://doi.org/10.1111/j.1365-2648.2009.05111.x

[7] van Adrichem, E.J., Dekker, R., Krijnen, W.P., et al. (2018) Physical Activity, Sedentary Time, and Associated Factors in Recipients of Solid-Organ Transplantation. Physical Therapy, 98, 646-657. https://doi.org/10.1093/ptj/pzy055

[8] Institute of Medicine Committee on Identifying Priority Areas for Quality (2003) In: Adams, K. and Corrigan, J.M. Eds., Priority Areas for National Action: Transforming Health Care Quality, National Academies Press, Washington DC, 52-53.

[9] De Bleser, L., Matteson, M., Dobbels, F., Russell, C. and De Geest, S. (2009) Interventions to Improve Medication-Adherence after Transplantation: A Systematic Review. Transplant International, 22, 780-797.

https://doi.org/10.1111/j.1432-2277.2009.00881.x

[10] De Geest, S., Burkhalter, H., Bogert, L., Berben, L., Glass, T.R. and Denhaerynck, K. (2014) Describing the Evolution of Medication Nonadherence from Pretransplant until 3 Years Post-Transplant and Determining Pretransplant Medication Nonadherence as a Risk Factor for Post-Transplant Nonadherence to Immunosuppressives: The Swiss Transplant Cohort Study. Transplant International, 27, 657-666. https://doi.org/10.1111/tri.12312

[11] Kidney Disease: Improving Global Outcomes (KDIGO) Transplant Work Group (2009) KDIGO Clinical Practice Guideline for the Care of Kidney Transplant Recipients. American Journal of Transplantation, 9, S1-S155. https://doi.org/10.1111/j.1600-6143.2009.02834.x

[12] Campbell, S.M., Braspenning, J., Hutchinson, A. and Marshall, M. (2002) Research Methods Used in Developing and Applying Quality Indicators in Primary Care. BMJ Quality \& Safety, 11, 358-364. https://doi.org/10.1136/qhc.11.4.358

[13] Jeffs, L., Law, M.P., Straus, S., Cardoso, R., Lyons, R.F. and Bell, C. (2013) Defining Quality Outcomes for Complex-Care Patients Transitioning across the Continuum Using a Structured Panel Process. BMJ Quality \& Safety, 22, 1014-1024. https://doi.org/10.1136/bmjqs-2012-001473

[14] Lynn M.R. (1986) Determination and Quantification of Content Validity. Nursing Research, 35, 382-386. https://doi.org/10.1097/00006199-198611000-00017

[15] Polit, D.F. and Beck, C.T. (2003) Nursing Research: Principles and Methods. 7th Edition, Lippincott Williams \& Wilkins, Philadelphia.

[16] Keeney, S., McKenna, H. and Hasson, F. (2011) The Delphi Technique in Nursing and Health Research. Wiley, Hoboken. https://doi.org/10.1002/9781444392029

[17] Raskin, M.S. (1994) The Delphi Study in Field Instruction Revisited: Expert Consensus on Issues and Research Priorities. Journal of Social Work Education, 30, 75 89. https://doi.org/10.1080/10437797.1994.10672215

[18] Rayens, M.K. and Hahn, E.J. (2000) Building Consensus Using the Policy Delphi Method. Policy, Politics, \& Nursing Practice, 1, 308-315. https://doi.org/10.1177/152715440000100409

[19] Green, B., Jones, M., Hughes, D. and Williams, A. (1999) Applying the Delphi Technique in a Study of GPs' Information Requirements. Health \& Social Care in the Community, 7,198-205. https://doi.org/10.1046/j.1365-2524.1999.00176.x

[20] Biondo, P.D., Nekolaichuk, C.L., Stiles, C., Fainsinger, R. and Hagen, N.A. (2008) 
Applying the Delphi Process to Palliative Care Tool Development: Lessons Learned. Supportive Care in Cancer, 16, 935-942. https://doi.org/10.1007/s00520-007-0348-2

[21] Huang, H.C., Lin, W.C. and Lin, J.D. (2008) Development of a Fall-Risk Checklist Using the Delphi Technique. Journal of Clinical Nursing, 17, 2275-2283.

https://doi.org/10.1111/j.1365-2702.2008.02337.x

[22] Fowler, K. (2017) Innovation in Chronic Kidney Disease: The Need for the Patient Voice. The Patient-Patient-Centered Outcomes Research, 10, 673-676. https://doi.org/10.1007/s40271-017-0281-5

[23] Adhikari, U.R., Taraphder, A., Hazra, A., et al. (2017) Medication Adherence in Kidney Transplant Recipients in an Urban Indian Setting. Journal of Nephrology, 27, 294-300. https://doi.org/10.4103/0971-4065.202835

[24] Leite, R.F., Máximo Silva, A.C., de Oliveira, P.C., et al. (2018) Measurement of Adherence to Immunosuppressive Drugs in Renal Transplant Recipients. Acta Paulista de Enfermagem, 31, 489-496. https://doi.org/10.1590/1982-0194201800069

[25] de Oliveira Marsicano, E., da Silva Fernandes, N., dos Santos Grincenkov, F.R., da Silva Fernandes, N.M., De Geest, S. and Sanders-Pinheiro, H. (2013) Validation of the Brazilian-Portuguese Version of the Basel Assessment of Adherence to Immunosuppressives Scale (BAASIS) in Kidney Transplants. BMC Nephrology, 14, Article No. 108. https://doi.org/10.1186/1471-2369-14-108

[26] Greenwood, S.A., Koufaki, P., Mercer, T.H., et al. (2015) Aerobic or Resistance Training and Pulse Wave Velocity in Kidney Transplant Recipients: A 12-Week Pilot Randomized Controlled Trial (the Exercise in Renal Transplant [ExeRT] Trial). American Journal of Kidney Diseases, 66, 689-698. https://doi.org/10.1053/j.ajkd.2015.06.016

[27] Byambasukh, O., et al. (2020) Physical Activity and the Development of Post-Transplant Diabetes Mellitus, and Cardiovascular- and All-Cause Mortality in Renal Transplant Recipients. Journal of Clinical Medicine, 9, Article No. 415. https://doi.org/10.3390/jcm9020415

[28] Lin, S.Y., Fetzer, S.J., Lee, P.C., et al. (2011) Predicting Adherence to Health Care Recommendations Using Health Promotion Behaviours in Kidney Transplant Recipients within 1-5 Years Post-Transplant. Journal of Clinical Nursing, 20, 3313-3321. https://doi.org/10.1111/j.1365-2702.2011.03757.x

[29] Low, J.K., Crawford, K., Manias, E. and Williams, A. (2017) Stressors and Coping Resources of Australian Kidney Transplant Recipients Related to Medication Taking: a Qualitative Study. Journal of Clinical Nursing, 26, 1495-1507. https://doi.org/10.1111/jocn.13435

[30] Lonargáin, D.Ó., Brannigan, D. and Murray, C. (2017) The Experience of Receiving a Kidney Transplant from a Deceased Donor: Implications for Renal Services. Psychology \& Health, 32, 204-220. https://doi.org/10.1080/08870446.2016.1254214

[31] Schmid-Mohler, G., Schäfer-Keller, P., Frei, A., Fehr, T. and Spirig, R. (2014) A MixedMethod Study to Explore Patients' Perspective of Self-Management Tasks in the Early Phase after Kidney Transplantation. Progress in Transplantation, 24, 8-18. https://doi.org/10.7182/pit2014728 